$63^{\text {ème }}$ Congrès de la SFCO, 01003 (2015)

DOI:10.1051/sfco/20156301003

(C) Owned by the authors, published by EDP Sciences, 2015

\title{
CONFÉRENCE
}

\section{Les corticotomies aujourd'hui : une chirurgie orthognatique mineure}

\section{Ernenwein D}

CHU Robert Debré, Paris, France

dr.ernenwein@maxillo-paris.com

La corticotomie est un geste chirurgical simple permettant de faciliter et d'accélérer le traitement orthodontique. Lorsqu'une greffe osseuse y est adjointe (Wilcko 1999), les corticotomies sont alors un moyen de sécuriser le parodonte lors du traitement orthodontique. Cette sécurisation parodontale associée à la facilitation du traitement orthodontique permet d'envisager une augmentation du champ de traitement des malocclusions.

L'objet de cette présentation est de réaliser un point sur l'utilisation des corticotomies dans le traitement orthodontique en 2015 et d'en envisager les limites.

L'enveloppe de mouvement classique d'une dent traitée orthodontiquement est ainsi presque doublée. Cette enveloppe de mouvement augmentée et sécurisée sur le plan parodontal permet de déplacer les curseurs des indications des traitements ortho-chirurgicaux.

Tout en restant sur des mouvements strictement alvéolaires et sans modification des bases osseuses, cette chirurgie permet d'éviter les ostéotomies pour des petits déplacements dans les cas « limites ».

This is an Open Access article distributed under the terms of the Creative Commons Attribution License 4.0, which permits unrestricted use, distribution, and reproduction in any medium, provided the original work is properly cited. 